\title{
Consumption of dairy products in the European Prospective Investigation into Cancer and Nutrition (EPIC) cohort: data from 35955 24-hour dietary recalls in 10 European countries
}

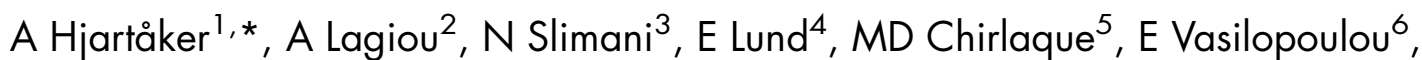
X Zavitsanos ${ }^{6}$, F Berrino $^{7}$, C Sacerdote ${ }^{8}$, MC Ocké $^{9}$, PHM Peeters $^{10}$, D Engeset ${ }^{4}$, G Skeie $^{4}$, A Aller ${ }^{11}, \mathrm{PAmiano}^{12}$, G Berglund ${ }^{13}$, S Nilsson ${ }^{14}$, A McTaggart ${ }^{15}$, EA Spencer ${ }^{16}$, $\mathrm{K}$ Overvad ${ }^{17}$, A Tjønneland ${ }^{18}$, F Clavel-Chapelon ${ }^{19}$, J Linseisen ${ }^{20}$, M Schulz $^{21}$, B Hemon ${ }^{3}$ and $\mathrm{E}$ Riboli $^{3}$

${ }^{1}$ Section of Medical Statistics, University of Oslo, PO Box 1122 , Blindern, N-0317 Norway: ${ }^{2}$ Department of Nutrition and Biochemistry, National School of Public Health, Greece: ${ }^{3}$ Unit of Nutrition and Cancer, International Agency for Research on Cancer, Lyon, France: ${ }^{4}$ Institute of Community Medicine, University of Tromsø, Norway: ${ }^{5}$ Council for Health and Social Affairs of Murcia, Spain: ${ }^{6}$ Department of Hygiene and Epidemiology, School of Medicine, University of Athens, Greece: ${ }^{7}$ Epidemiology Unit, National Cancer Institute, Milan, Italy: ${ }^{8}$ Unit of Cancer Epidemiology, Hospital S. Giovanni and CPO-Piemonte, Turin, Italy: ${ }^{9}$ Department of Chronic Diseases Epidemiology, National Institute for Public Health and the Environment, Bilthoven, The Netherlands: ${ }^{10}$ Julius Center for General Practice and Patient Oriented Research, University of Utrecht, The Netherlands: ${ }^{11}$ Council for Health and Sanitary Services of the Principality of Asturias, Oviedo, Spain: ${ }^{12}$ Public Health Division of Gipuzkoa, Department of Health of the Basque Government, San Sebastian, Spain: ${ }^{13}$ Department of Medicine, Lund University, Malmö University Hospital, Sweden: ${ }^{14}$ Department of Public Health and Clinical Medicine, Umeå University, Sweden: ${ }^{15}$ Department of Public Health and Primary Care, School of Clinical Medicine, University of Cambridge, UK: ${ }^{16}$ Cancer Research UK, Epidemiology Unit, University of Oxford, UK: ${ }^{17}$ Department of Epidemiology and Social Medicine, University of Aarhus, Denmark: ${ }^{18}$ Institute of Cancer Epidemiology, Danish Cancer Society, Copenhagen, Denmark: ${ }^{19}$ INSERM, E3N-EPIC Group, Institute Gustave Roussy, Villejuif, France: ${ }^{20}$ Division of Clinical Epidemiology, German Cancer Research Centre, Heidelberg, Germany: ${ }^{21}$ German Institute of Human Nutrition, Department of Epidemiology, Potsdam-Rehbrücke, Germany
\end{abstract}

\begin{abstract}
Objectives: To describe and compare the consumption of dairy products in cohorts included in the European Prospective Investigation into Cancer and Nutrition (EPIC). Methods: Data from single 24-hour dietary recall interviews collected through a highly standardised computer-based program (EPIC-SOFT) in 27 redefined centres in 10 European countries between 1995 and 2000. From a total random sample of 36900 , 22924 women and 13031 men were selected after exclusion of subjects under 35 and over 74 years of age.

Results: A high total consumption of dairy products was reported in most of the centres in Spain and in the UK cohort sampled from the general population, as well as in the Dutch, Swedish and Danish centres. A somewhat low consumption was reported in the Greek centre and in some of the Italian centres (Ragusa and Turin). In all centres and for both sexes, milk constituted the dairy sub-group with the largest proportion (in grams) of total dairy consumption, followed by yoghurt and other fermented milk products, and cheese. Still, there was a wide range in the contributions of the different dairy sub-groups between centres. The Spanish and Nordic centres generally reported a high consumption of milk, the Swedish and Dutch centres reported a high consumption of yoghurt and other fermented milk products, whereas the highest consumption of cheese was reported in the French centres.

Conclusion: The results demonstrate both quantitative and qualitative disparities in dairy product consumption among the EPIC centres. This offers a sound starting point for analyses of associations between dairy intake and chronic diseases such as cancer.
\end{abstract}

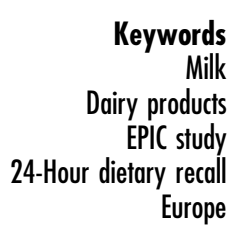


Dairy products constitute an important part of the diet in many Western countries. The food group includes a wide variety of food items all based on some kind of milk, in Western societies predominantly cows' milk. Commonly used dairy products in addition to milk are yoghurt, cheese, ice cream and butter.

Generally, dairy products are considered to be an important source of saturated fatty acids, the principal dietary source of conjugated linoleic acid and a major source of trans-fatty acids in populations with a low consumption of partially hydrogenated oils. Still, the fat content of items included in the dairy group varies tremendously, from almost $0 \%$ in skimmed milk to more than $80 \%$ in butter. The increasing supply of so-called light dairy products also gives rise to a large variation in the fat content within the different sub-groups of dairy products (e.g. full-fat cheeses vs. low-fat cheeses) and makes global statements on nutrient content difficult and inappropriate. Because of the large variation in fat, there is also a huge variation in the content of lipid soluble components. For instance, the level of vitamin A (retinol) may vary from $1 \mu \mathrm{g} / 100 \mathrm{~g}$ in skimmed milk to more than $600 \mu \mathrm{g} / 100 \mathrm{~g}$ in butter. Milk, cheese and yoghurt are essential contributors to the dietary intake of calcium and they are also significant contributors to the intakes of riboflavin (vitamin $\mathrm{B}_{2}$ ) and vitamin $\mathrm{B}_{12}$.

Regarding associations relating the consumption of dairy products with chronic diseases, in Western societies consumption of dairy products has traditionally been linked to cardiovascular diseases (arteriosclerosis) ${ }^{1}$ and osteoporosis $^{2,3}$ owing to their saturated fatty acids and calcium content, respectively. While the association between saturated fat intake and risk of arteriosclerosis is well established ${ }^{4,5}$, the association between calcium from dairy products, together with vitamin D, and osteoporosis is less clear ${ }^{6}$.

Associations between consumption of dairy products and cancer have been examined very little. A report by the World Cancer Research Fund and the American Institute for Cancer Research, published in $1997^{7}$, states that no judgement can yet be made for associations between consumption of dairy products and risk of cancer, the exception being a possible positive association with kidney $^{8,9}$ and prostate cancers ${ }^{10-12}$. However, a number of components of dairy products have been hypothesised to be linked to carcinogenesis based on animal or experimental studies ${ }^{13}$. Among the suggested components are calcium ${ }^{14}$, phosphate ${ }^{10}$, vitamin $\mathrm{D}^{10}$, lactose $\mathrm{e}^{15}$, saturated fatty acids ${ }^{16}$, butyric acid ${ }^{17}$, conjugated linoleic $\operatorname{acid}^{18}$, whey protein ${ }^{19}$ and lactic acid bacteria ${ }^{20}$. Also, consumption of milk has been found to raise serum levels of insulin-like growth factor-I, which in turn may increase cancer risk ${ }^{21}$. The fact that dairy products contain both components that have been hypothesised to increase the risk of cancer and components that have been hypothesised to reduce the risk of cancer, makes this food group one of particular interest. For instance, saturated fats have been linked to increased risk of lung ${ }^{22}$ and prostate cancers $^{16}$, whereas conjugated linoleic acid has been linked to a reduced risk of breast cancer, at least in animal studies $^{23,24}$.

In order to understand whether and how consumption of dairy products may be related to chronic diseases, particularly cancer, a more detailed approach to this heterogeneous food group may be necessary. In this paper we present data on the consumption of dairy products in 10 European countries participating in a large cohort study on diet and cancer, the European Prospective Investigation into Cancer and Nutrition (EPIC). This study uses a common methodology to collect dietary information on the individual level and provides an opportunity to evaluate dietary exposure across countries. The current data were collected by means of a highly standardised 24-hour dietary recall interview, a method suitable for estimation of group intake and for comparisons between different groups ${ }^{25,26}$. The specific aim of this paper was to describe and compare the consumption of dairy products across the EPIC centres.

\section{Materials and methods}

\section{The EPIC study}

EPIC is a multi-centre cohort study designed to investigate the relationships between diet, nutritional and metabolic characteristics, lifestyle factors and risk of cancer. It aims to increase the between-subject variance by including various populations and to decrease the level of random measurement errors by using a common methodology ${ }^{27}$. The study was conducted in Greece, Spain, Italy, France, Germany, the Netherlands, the UK, Denmark, Sweden and Norway. Currently, the study involves 519978 participants aged 20 years and over, with most of the participants in the age range 35-74 years. In most countries, no attempt was made to recruit a country-representative study sample, but rather to concentrate on selected geographical areas or on selected population sub-groups (e.g. teachers and school workers in France, 'health-conscious' subjects in the UK). In total 27 centres were defined for the present analyses. Details about definition of the centres are given elsewhere in this supplement ${ }^{28,29}$. All centres recruited both male and female participants, except the centres in France, Norway, Utrecht (The Netherlands) and Naples (Italy), which studied female participants only.

Dietary data were collected using different dietary history or food-frequency questionnaires developed and validated in each country ${ }^{30-33}$. To calibrate dietary data collected by the different methods, a single 24-hour dietary recall interview was performed in a sub-sample of the participants. By applying the calibration data on the country-specific data, one can achieve adjustment for systematic over- or underestimation of dietary intake on a group level ${ }^{34}$. 
The EPIC cohort and the study rationale are described more thoroughly elsewhere in this supplement ${ }^{28,29}$.

\section{Subjects}

The present analyses are based on data from the calibration study collected between 1995 and 2000. The calibration sub-cohort constitutes a stratified random sample of each country's cohort in proportion to the expected number of cancer cases by age and sex, and consists of 36900 subjects. For the present analyses, the study sample was restricted to participants aged 35-74 years, giving a total of 35955 24-hour dietary recalls (13031 men and 22924 women).

\section{4-Hour dietary recalls}

The recalls were performed using the computer program EPIC-SOFT $^{34,35}$, which was developed by the International Agency for Research on Cancer to ensure standardisation of the interviews. In co-operation with each participating country, country-specific versions of the program were developed. Depending on the country, 1500-2000 foods and 150-300 recipes were entered into the software. During the interview, each reported food item was automatically described and quantified according to common criteria. The amount consumed by the subject was quantified by means of photographs, standard units, household measures or exact amount (grams or millilitres), if the subject knew this. A single 24-hour dietary recall was completed per person. All interviews were performed in a face-to-face setting, except in Norway where the interviews were conducted by telephone ${ }^{36}$. More information on the 24-hour dietary recall procedures are given elsewhere ${ }^{34,35}$.

\section{Data on dairy consumption}

This paper concentrates on the consumption of dairy products, while the consumption of other foods is described in other papers in this supplement ${ }^{37-43}$. In EPIC-SOFT, dairy products are categorised into the following sub-groups: 'milk', 'milk beverages', 'yoghurt', 'fromage blanc and petits suisses' (fresh cheeses), 'cheeses', 'cream desserts and milk-based puddings', 'dairy creams', 'creamers and milk for coffee', 'butter' and 'ice cream'. In the context of this paper, only the main sub-groups ('milk', 'yoghurt', 'cheeses', 'cream desserts and milk-based puddings', 'butter' and 'ice cream') are described in detail.

An effort was made to look more closely into fermented products. All dairy items were re-classified into the new categories 'non-fermented', 'fermented during processing, but with little living bacteria in the ready-to-eat product' or 'fermented and with a significant amount of living bacteria in the ready-to-eat product'. It turned out, however, that such a classification was problematic, because of the unclear boundaries between the categories and because the content of bacteria in a given product changes constantly from the time of production until it is consumed. Also, as yoghurt and fermented milk products included in the EPIC-SOFT sub-group 'yoghurt' were by far the greatest constituent of consumed fermented products ('significant amounts of living bacteria in the ready-to-eat product'), we decided to retain the EPICSOFT classification, but change the name of the sub-group from 'yoghurt' to 'yoghurt and other fermented milk products'.

The calculated figures add up the total intake of each food, i.e. consumption of a food eaten both as an item and as an ingredient. The figures are given as grams per day. Furthermore, the sub-groups are presented in terms of their percentage contribution to total dairy intake.

\section{Statistical analyses}

All statistical analyses were stratified by gender. Crude and adjusted mean daily intakes were calculated for each centre. Adjusted means were calculated by means of an analysis of covariance approach, using a weighted regression model with weights at the individual level, as suggested by Kleinbaum et al. ${ }^{44}$. Based on the results from preparatory analyses, we decided to include the following variables in the multiple regression models: age (continuous), season (four categories) and day of the week (two categories: Monday-Friday and Saturday-Sunday). Regression models adjusting for total energy intake (continuous) were also performed. Statistical analyses were done by means of the SAS software package, version 6.12 .

\section{Results}

Table 1 presents the reported daily consumption of dairy products; both crude mean values and mean values after adjustment for age, season and day of the week are given. Since the crude and adjusted values did not differ significantly, only the adjusted values are referred to in the text. For both sexes, the total amount of dairy products consumed varied substantially between the centres. For females it ranged from about $150 \mathrm{~g} \mathrm{day}^{-1}$ in Ragusa (Italy) to nearly $480 \mathrm{~g} \mathrm{day}^{-1}$ in Asturias (Spain). For males, the lowest consumption was also reported in Ragusa with about $160 \mathrm{~g} \mathrm{day}^{-1}$, while the highest consumption was reported in Umeå (Sweden) with about $480 \mathrm{gday}^{-1}$. Together with Greece, a low total dairy consumption was also found in the other Italian centres, whereas a high consumption was found in the Spanish centres, particularly among women, in Utrecht (The Netherlands, women only) and in the British cohort sampled from the general population.

For women, the reported energy intake ranged from $1515 \mathrm{kcal} \mathrm{day}^{-1}$ (Greece) to $2092 \mathrm{kcal} \mathrm{day}^{-1}$ (San Sebastian, Spain), while for men the energy intake ranged from $2122 \mathrm{kcal} \mathrm{day}^{-1}$ (Greece) to $3077 \mathrm{kcal} \mathrm{day}^{-1}$ (San Sebastian, Spain) (data not shown). Additional adjustment for 
Table 1 Reported daily consumption (g) of dairy products* in the European Prospective Investigation into Cancer and Nutrition (EPIC) centres, crude and adjusted means

\begin{tabular}{|c|c|c|c|c|c|c|c|c|}
\hline \multirow[b]{3}{*}{ Country and centre } & \multirow[b]{3}{*}{$n$} & \multicolumn{3}{|c|}{ Women $(n=22924)$} & \multirow[b]{3}{*}{$n$} & \multicolumn{3}{|c|}{$\operatorname{Men}(n=13031)$} \\
\hline & & \multirow[b]{2}{*}{ Crude mean } & \multicolumn{2}{|c|}{ Adjusted $\dagger$} & & \multirow[b]{2}{*}{ Crude mean } & \multicolumn{2}{|c|}{ Adjusted† } \\
\hline & & & Mean & SE & & & Mean & SE \\
\hline \multicolumn{9}{|l|}{ Greece } \\
\hline Greece & 1374 & 188.7 & 187.6 & 6.3 & 1312 & 189.8 & 187.2 & 7.7 \\
\hline \multicolumn{9}{|l|}{ Spain } \\
\hline Granada & 300 & 381.7 & 385.2 & 13.5 & 214 & 382.0 & 385.3 & 18.9 \\
\hline Murcia & 304 & 334.9 & 335.7 & 13.4 & 243 & 251.3 & 244.9 & 17.8 \\
\hline Navarra & 271 & 395.1 & 397.2 & 14.2 & 444 & 281.5 & 284.2 & 13.1 \\
\hline San Sebastian & 244 & 397.5 & 399.4 & 15.0 & 490 & 329.6 & 332.4 & 12.6 \\
\hline Asturias & 324 & 478.1 & 476.4 & 13.0 & 386 & 416.9 & 420.5 & 14.1 \\
\hline \multicolumn{9}{|l|}{ Italy } \\
\hline Ragusa & 138 & 159.6 & 153.0 & 19.9 & 168 & 168.9 & 162.5 & 21.4 \\
\hline Naples & 403 & 196.4 & 200.5 & 11.6 & - & - & - & - \\
\hline Florence & 785 & 211.6 & 212.6 & 8.3 & 271 & 215.2 & 211.1 & 16.8 \\
\hline Turin & 392 & 194.8 & 194.6 & 11.8 & 677 & 191.8 & 189.8 & 10.7 \\
\hline Varese & 794 & 240.6 & 236.8 & 8.3 & 328 & 250.1 & 268.7 & 15.3 \\
\hline \multicolumn{9}{|l|}{ France } \\
\hline South coast & 612 & 289.5 & 298.9 & 9.5 & - & - & - & - \\
\hline South & 1396 & 289.0 & 287.7 & 6.3 & - & - & - & - \\
\hline North-west & 622 & 288.2 & 287.8 & 9.4 & - & - & - & - \\
\hline North-east & 2009 & 296.7 & 296.4 & 5.2 & - & - & - & - \\
\hline \multicolumn{9}{|l|}{ Germany } \\
\hline Heidelberg & 1087 & 251.4 & 252.2 & 7.2 & 1033 & 242.6 & 234.3 & 8.7 \\
\hline Potsdam & 1063 & 251.4 & 243.7 & 7.2 & 1235 & 247.8 & 247.4 & 7.9 \\
\hline \multicolumn{9}{|l|}{ The Netherlands } \\
\hline Bilthoven & 1086 & 331.9 & 330.6 & 7.2 & 1024 & 369.7 & 367.8 & 9.0 \\
\hline Utrecht & 1874 & 429.6 & 430.3 & 5.4 & - & - & - & - \\
\hline \multicolumn{9}{|l|}{ United Kingdom } \\
\hline General population & 571 & 365.8 & 366.2 & 9.8 & 404 & 404.1 & 408.1 & 13.8 \\
\hline 'Health-conscious' & 197 & 237.8 & 215.6 & 16.6 & 114 & 198.3 & 215.7 & 25.9 \\
\hline \multicolumn{9}{|l|}{ Denmark } \\
\hline Copenhagen & 1485 & 285.3 & 285.5 & 6.1 & 1356 & 341.3 & 338.7 & 7.5 \\
\hline Aarhus & 510 & 312.9 & 309.7 & 10.3 & 567 & 363.6 & 359.2 & 11.6 \\
\hline \multicolumn{9}{|l|}{ Sweden } \\
\hline Malmö & 1711 & 304.9 & 305.6 & 5.8 & 1421 & 336.5 & 342.6 & 7.7 \\
\hline Umeå & 1574 & 366.8 & 370.3 & 5.9 & 1344 & 471.9 & 481.1 & 7.6 \\
\hline \multicolumn{9}{|l|}{ Norway } \\
\hline South \& East & 1136 & 291.9 & 289.0 & 7.0 & - & - & - & - \\
\hline North \& West & 662 & 285.4 & 286.8 & 9.2 & - & - & - & - \\
\hline
\end{tabular}

SE - standard error.

*Dairy products include milk, milk beverages, yoghurt, cheeses, fromage blancs and petits suisses, cream desserts and milk-based puddings, ice cream, butter, dairy creams, and creamers and milk for coffee.

$\dagger$ Adjusted for age, season and day of the week.

total energy did not, in general, change the figures on dairy intake and this methodological issue will not be pursued further. It should be noted, however, that for the Greek data, adjustment for energy intake did increase the figures to some extent (i.e. from $188 \mathrm{~g} \mathrm{day}^{-1}$ to $220 \mathrm{~g} \mathrm{day}^{-1}$ for women and from $187 \mathrm{~g} \mathrm{day}^{-1}$ to $216 \mathrm{~g} \mathrm{day}^{-1}$ for men).

In all centres and for both sexes, 'milk' constituted the most commonly consumed dairy sub-group, i.e. the largest amount consumed expressed as a proportion (\%) of the total daily consumption of dairy products (g) (Tables $2 \mathrm{a}$ and $2 \mathrm{~b}$ ). The second largest sub-group was 'yoghurt and other fermented milk products', and the third largest sub-group 'cheeses'. In the Spanish centres, 'milk' constituted $74-83 \%$ of total daily dairy intake, while in the French centres it made up no more than 34-39\%. For the French participants, on the other hand, 'yoghurt and other fermented milk products' constituted a significant part of the total daily dairy intake (about one-quarter). 'Yoghurt and other fermented milk products' were also important contributors to the total consumption of dairy products in the Swedish centres of Malmö and Umeå (18-32\%). Generally, women appeared to obtain a higher proportion of their dairy consumption from 'yoghurt and other fermented milk products' than did men. 'Milk beverages' (e.g. milky drinks) constituted a minor proportion of dairy consumption, except in the British centres and to some extent in the German centre of Potsdam. The highest contribution was calculated for the British 'healthconscious' cohort, where 'milk beverages' constituted $13-16 \%$ of the daily intake of dairy products. 'Fromage blanc and petits suisses' constituted nearly $10 \%$ of the daily dairy intake in the French centres and about $6 \%$ in the German centres, while the contribution from this food group was low in the other centres. The contribution from 


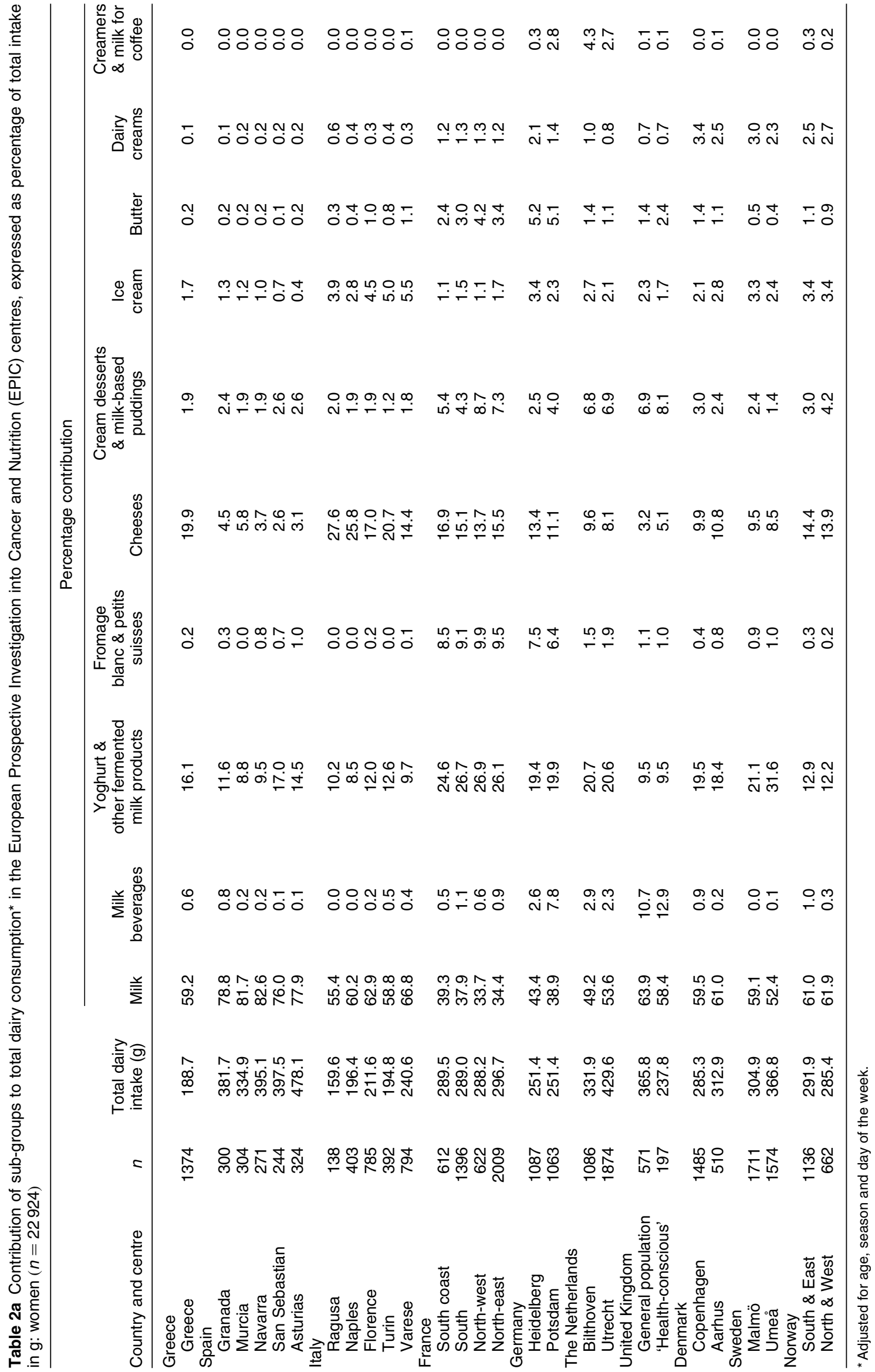




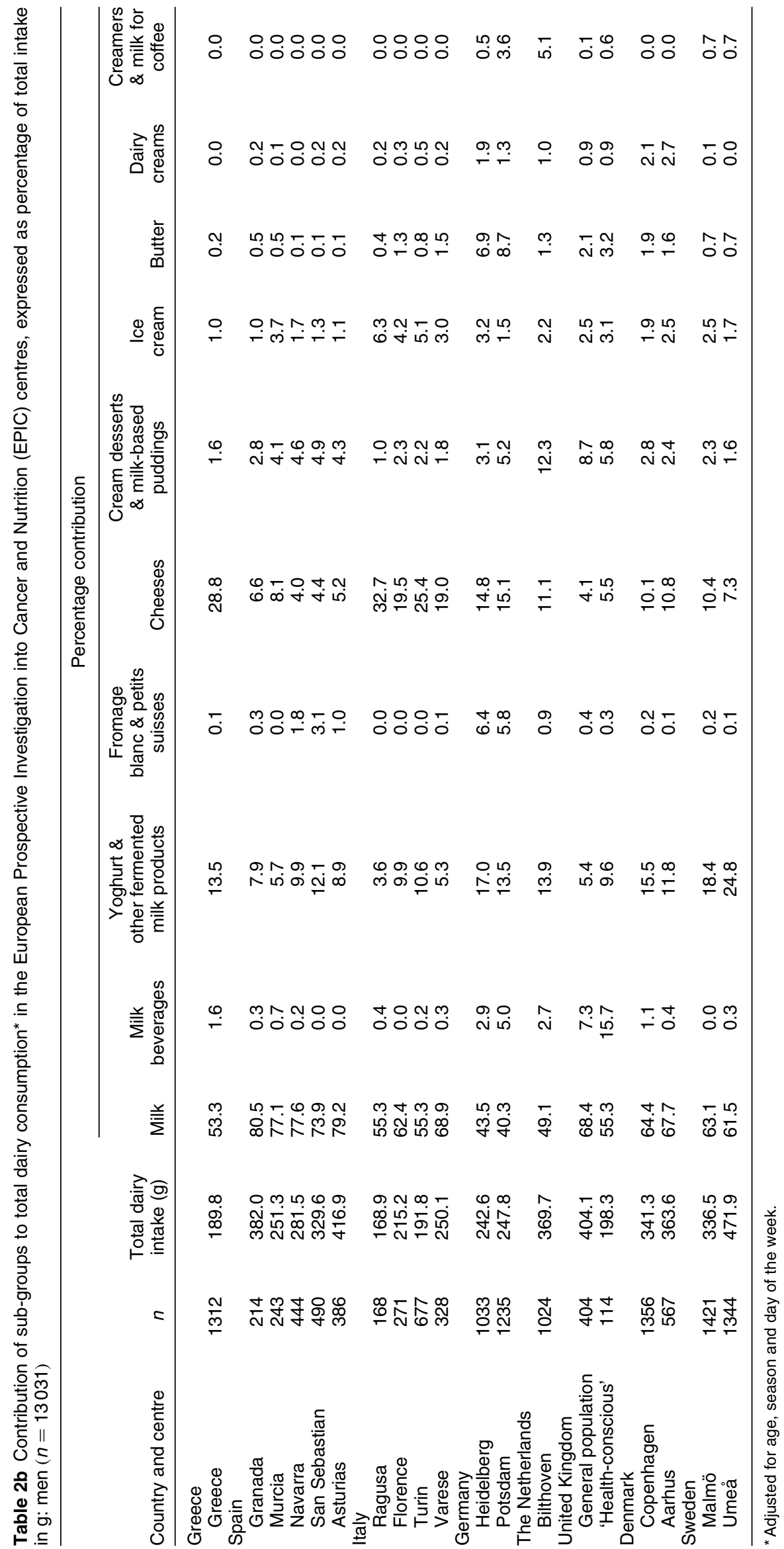




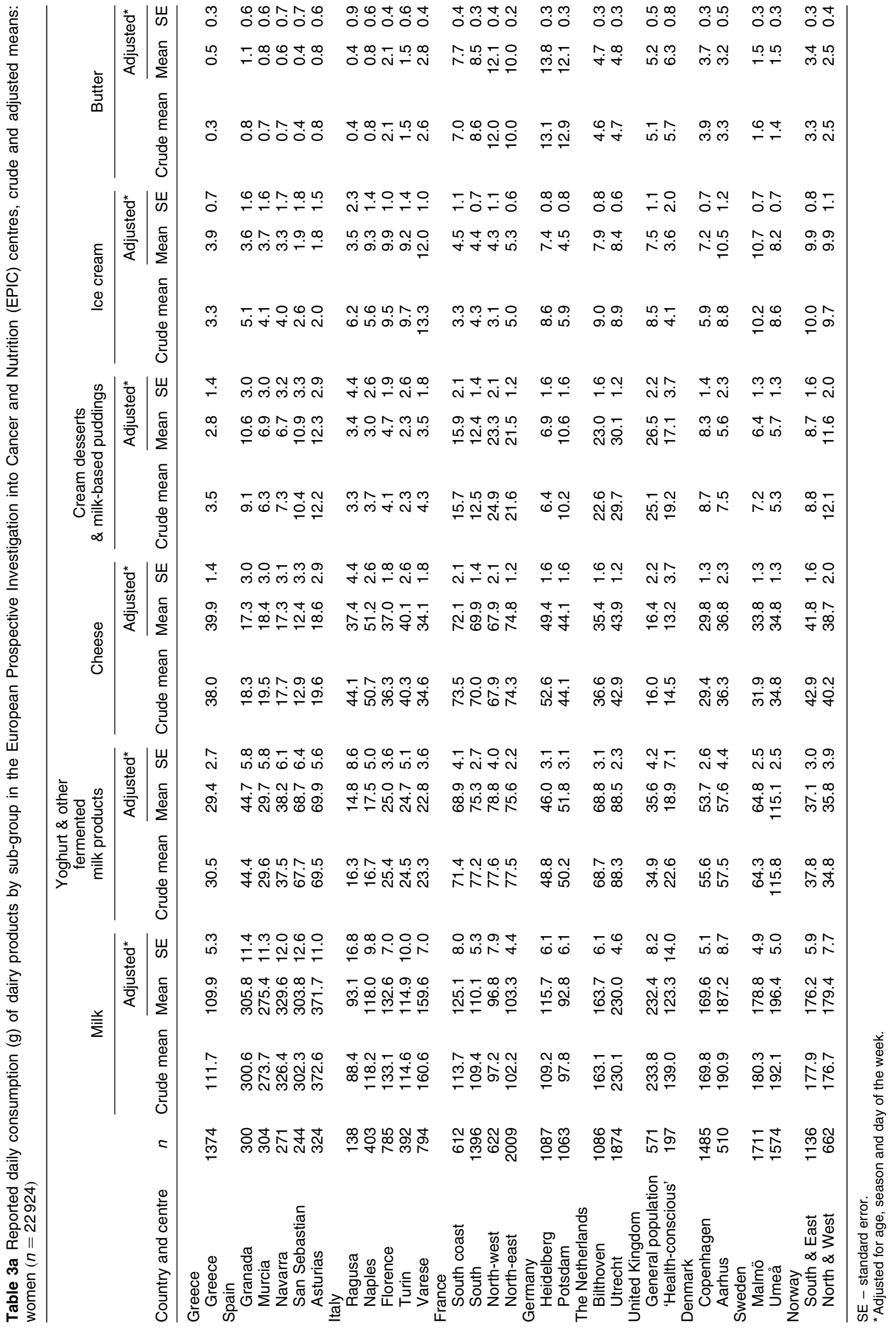


'cheeses' varied highly between the centres, ranging from $6 \%$ or less in the British and in some of the Spanish centres, to $25-33 \%$ in the Italian centres of Ragusa, Turin and Naples. A high contribution was also found in Greece, particularly among men (29\%). 'Cream desserts and milkbased puddings' contributed between $2-5 \%$ of daily dairy consumption in most centres, but with a higher contribution in the French (except in the South), British and Dutch centres (5-12\%). The highest contribution from 'ice cream' was reported in the Italian centres, where it contributed $3-6 \%$ of the daily dairy intake. With the exception of the Italian centres, there was some tendency for 'ice cream' to contribute more to the daily dairy consumption in the centres of northern Europe than for the centres in the south. The contribution from 'butter' was highest in the German centres (5-9\%), followed by the French (2-4\%) and British centres (1-3\%). There was some tendency for 'butter' to constitute a higher proportion of the dairy intake among men than among women. As for the two last sub-groups, 'dairy creams' and 'creamers and milk used for coffee', the contribution was low in all centres. The contribution from 'dairy creams' was highest in the Nordic centres (2-3\%), whereas the contribution from 'creamers and milk used for coffee' was highest in the Dutch centres and in the German centre of Potsdam (3-5\%).

Tables $3 \mathrm{a}$ and $3 \mathrm{~b}$ present the mean daily reported consumption of the main dairy sub-groups. The lowest consumption of 'milk' was reported in the Sicilian centre of Ragusa, the German centre of Potsdam, the centres Northeast and North-west France and in the Greek centre. In these centres the reported consumption of 'milk' was below or just above $100 \mathrm{~g} \mathrm{day}^{-1}$. It should be noted that the reported energy intake in the Greek cohort was rather low and that adjustment for energy therefore increased the Greek figures to some extent (from 110 and $94 \mathrm{~g} \mathrm{day}^{-1}$ to 127 and $110 \mathrm{~g} \mathrm{day}^{-1}$ for women and men, respectively). The highest 'milk' consumption was reported in the Spanish centres, particularly among women ( $\geq 275 \mathrm{~g} \mathrm{day}^{-1}$ in all centres); the highest consumption was found among women in Asturias, who on average reported consuming $370 \mathrm{~g}$ of 'milk' per day. A high consumption of 'milk' was also reported among the Swedish men of the Umeå centre $\left(300 \mathrm{~g} \mathrm{day}^{-1}\right)$.

Participants from the Swedish centre of Umeå, both men and women, reported a considerably higher intake of 'yoghurt and other fermented milk products' (115 $\mathrm{g} \mathrm{day}^{-1}$ ) than participants from the other EPIC centres. The consumption of 'yoghurt and other fermented milk products' was also significant among the females in the Dutch and French centres (70-90 $\mathrm{gday}^{-1}$ ). A low consumption of 'yoghurt and other fermented milk products' was reported in the Italian centres, while for the Spanish centres there was a wide diversity. Overall, women tended to report a higher consumption of 'yoghurt and other fermented milk products' than men.
Owing to the low consumption of 'fromage blanc and petits suisses' in most centres, the consumption of food items from this sub-group was, for all further analyses, combined with the consumption registered in the original sub-group 'cheeses' making a new sub-group, hereafter referred to as 'cheese'. The lowest consumption of 'cheese' was reported in the British cohort of so-called 'healthconscious' subjects $\left(12-13 \mathrm{~g} \mathrm{day}^{-1}\right)$, but even in the British cohort sampled from the general population, a low consumption was found $\left(16-19 \mathrm{~g} \mathrm{day}^{-1}\right)$. Also in the Spanish centres, the reported 'cheese' consumption was low, especially among women. For women, the highest consumption of 'cheese' was reported in the French centres (roughly $70 \mathrm{~g} \mathrm{day}^{-1}$ ), followed by the Italian centre of Naples $\left(51 \mathrm{~g} \mathrm{day}^{-1}\right)$ and the two German centres (44 and $49 \mathrm{~g} \mathrm{day}^{-1}$ ). For men, the highest consumption was reported in Greece $\left(58 \mathrm{~g} \mathrm{day}^{-1}\right)$, followed by the Italian centre of Ragusa $\left(53 \mathrm{~g} \mathrm{day}^{-1}\right)$ and the two German centres ( 48 and $51 \mathrm{~g} \mathrm{day}^{-1}$ ).

Comparing men and women from the same centre, men tended to have a slightly higher consumption of 'cream desserts and milk-based puddings' than did women. Comparisons between centres showed that the consumption of 'cream desserts and milk-based puddings' in some centres was more than 10 times higher than in other centres, the extremes being the consumption of $2 \mathrm{~g} \mathrm{day}^{-1}$ among men in Ragusa (Italy) vs. $47 \mathrm{~g} \mathrm{day}^{-1}$ among men in Bilthoven (The Netherlands). A low consumption was reported in all of the Italian centres and also among the Greek participants. A high consumption was reported in the Dutch, French and British centres, with the exception of men in the British 'health-conscious' sample.

In congruence with the figures on the sub-groups' percentage contribution to the total dairy consumption, the consumption of 'ice cream' in grams was highest in the Nordic and Italian centres and lowest in the Spanish centres. For centres with the highest figures, reported intake was of the order of $7-12 \mathrm{~g} \mathrm{day}^{-1}$ and for centres with the lowest figures, of the order of $2-4 \mathrm{~g} \mathrm{day}^{-1}$.

Generally, men reported a higher consumption of 'butter' than did women. For some of the centres, such as the Greek and Spanish ones, the consumption of 'butter' was about nil, while for most centres the consumption was between 2 and $5 \mathrm{gday}^{-1}$. A higher consumption was reported in the British, French and German centres. The highest consumption was found among German men, who reported eating more than $20 \mathrm{~g}$ of 'butter' per day.

\section{Discussion}

The present results show that the pattern of dairy consumption varies between the EPIC centres, both with respect to the total amount consumed as well as the relative importance of the different dairy sub-groups. Overall, the consumption pattern seems to vary more between countries than between centres within the same 
country, although there are exceptions. Also, there seem to be some parallels between the consumption patterns of men and women of the same centres. The Spanish and Nordic countries generally report a high consumption of 'milk', the Swedish (particularly Umeå) and Dutch centres report a high consumption of 'yoghurt and other fermented milk products', whereas the highest consumption of 'cheese' is reported in the French centres. 'Cream desserts and milk-based puddings' are consumed primarily in the UK general population group and in the Dutch centres, while the highest consumption of 'ice cream' is reported in the Italian and Nordic centres. As for 'butter', the highest consumption is reported in the German, UK and French centres. Interestingly, the data suggest that countries consuming lower quantities of milk (e.g. Greece and Germany) tend to consume higher quantities of cheese.

Even though the within-country variation may not be large, one should be very careful not to extrapolate data to the entire country, as in most cases it is not intended that the subjects make up a country-representative sample. Along with population-based samples in several centres and countries, there are centres with participants sampled from special groups such as blood donors, attendees at breast cancer screening (females) and subjects with an interest in vegetarian eating habits ${ }^{28}$.

A major strength of this study is the highly standardised method of collecting the dietary information. As the 24hour dietary recall method collects data in an open-ended way inconsistency between interviews may create bias, although this should not be a problem in the EPIC study. The interviewers were carefully trained, and while interviewing they were led step-by-step through the computer program. Probing questions were used comprehensively and amounts consumed - a critical component when performing 24-hour recalls - were quantified by means of photos and household measures. Also, as dietary intake may change during the week and with season and there was some imbalance in the sampling of the 24-hour recalls, day of the week and season were adjusted for in the analyses.

Twenty-four hour dietary recalls are prone to underestimation of total energy intake ${ }^{26}$. The subject may consciously or unconsciously leave out food items or report erroneously small portion sizes. In our analyses, adjusting for total energy intake barely influenced the calculated intake of dairy products. An exception to this finding was the Greek data, which increased by about 10 15\% after energy adjustment. A more thorough examination of underestimation in the 24-hour dietary recalls is presented elsewhere in this supplement ${ }^{45}$.

In situations where an expected association between a disease and dietary exposure does not appear, it is sometimes argued that this could be partly due to a too narrow range of exposure. The EPIC study, by including both northern and southern European countries and populations with different cultural dietary habits, enhances the chance of a wider range of exposure and thereby also the chance of revealing important associations. In the present material, the ratio between the highest and the lowest consumers of dairy products is about 3. The highest consumption is reported from the centres in Spain, Sweden and The Netherlands and the lowest from the centres in Italy and Greece. Overall, there might be a tendency towards a higher consumption in the northern Europe centres, but no clear north-south gradient appears. Still, one has to bear in mind that the aggregate variable 'dairy product' includes dairy products that differ tremendously with regard to energy, water and nutrient content. Thus, centres with a high total intake of dairy products due to a high intake of liquid milk, but with little cheese, may have the same or even lower intakes of nutrients (e.g. fat, calcium) than centres with a high intake of cheese, but with a lower total intake of dairy products due to a low consumption of liquid milk. Total consumption of dairy products may therefore not be appropriate when the primary interest is nutrient intake.

Use of the results of the EPIC calibration study to run international comparisons of dairy product consumption has the strong advantage of the administration of a standardised 24-hour dietary recall in all centres and the disadvantage of referring to population samples that were not intended to be, nor are, country-representative. Another source of comparable data on dairy product availability in 14 European countries is the DAFNE (DAta Food NEtworking) databank, which comprises food availability data collected with a similar methodology through national household budget surveys conducted with country-representative population samples ${ }^{46,47}$. The DAFNE data, referring to foods entering the household, are readily available on the Internet (DafneSoft program, http://www.nut.uoa.gr).

Direct comparisons of data on dairy products provided in the DAFNE and EPIC databases cannot be undertaken, because of the different nature of the two datasets. When ranking countries, however, both DAFNE and EPIC data indicate Greeks and Germans as consuming lower quantities of dairy products. In contrast to the EPIC data, in DAFNE the highest consumption of dairy products is recorded in Norway and not in Spain. Both DAFNE and EPIC data identify milk as the main constituent of the dairy product group. Based on this information, it is evident that DAFNE as well as EPIC data firmly document both qualitative and quantitative disparities in dairy product availability/consumption among European countries.

From a global perspective, food supply data derived from the Food and Agriculture Organization (FAO) ${ }^{48}$ indicate that Europe has the highest consumption of dairy products, with an annual per capita supply of $210 \mathrm{~kg}$ (butter excluded). Next in line are North America with $195 \mathrm{~kg}$, Oceania with $156 \mathrm{~kg}$, South America with $124 \mathrm{~kg}$, Asia with $41 \mathrm{~kg}$ and finally Africa with $36 \mathrm{~kg}$. Compared 
with the FAO's figures for dairy product supply 30 years ago, all continents have increased their supply, except North America and Oceania. For Europe, the annual per capita supply has increased by 18\% from 1961 to 1999 (from $178 \mathrm{~kg}$ to $210 \mathrm{~kg})^{48}$. However, in some of the countries participating in the EPIC study, there has been a decrease in the consumption of dairy products over the last 10 years (e.g. Sweden, Denmark), whereas for most of the countries total dairy consumption has shown stable figures. Still, within the total dairy group, the consumption of some products (e.g. milk) may have decreased, while the consumption of other products (e.g. cheese) may have increased. Figures on total dairy consumption may, therefore, as mentioned before, be too rough an estimate for evaluating trends in nutrient intake and also for evaluating trends in consumption of different dairy subgroup products.

The large variation in dairy product consumption around the world may be partly explained by different populations' ability to digest lactose into its sugar components, galactose and glucose ${ }^{49}$. The highest prevalence of hypolactasia is found in the Far East (90\%) and the lowest in north-western Europe $(5-10 \%)^{50,51}$. In the Mediterranean countries the prevalence varies, but is typically about $60-70 \% 0^{50,51}$.

Current knowledge concerning consumption of dairy products and risk of cancer is limited, and also quite diverse, regarding both different kinds of cancer and different components of dairy products. For instance, consumption of dairy products has been positively related to prostate cancer ${ }^{11,12}$ but negatively related to breast cancer $^{52,53}$; calcium intake has been negatively related to colorectal cancer ${ }^{21,54}$, but positively related to prostate cancer $^{11}$; and saturated fat and calcium have been linked to colorectal cancer positively and negatively, respectively $^{11,55,56}$.

In contrast to the rather low interest that has been shown in dairy products, a large number of studies have focused on the relationship between meat consumption and chronic diseases, such as cancer ${ }^{57}$. Generally, meat consumption has been linked to an increased risk of cancers, in particular to increased risk of colorectal cancer $^{58,59}$. An interesting question is whether consumption of dairy products correlates with consumption of meat and its products. A corresponding paper on consumption of meat in the EPIC study reports a high consumption in most of the Spanish centres and a low consumption in the 'health-conscious' group in the UK and the Greek centre ${ }^{39}$. This is in concordance with our findings on dairy product consumption. However, a high consumption of meat was also reported in the French centres, which had a relatively low consumption of dairy products, whereas the centres in Denmark ranked low on meat consumption and somewhat in the middle on dairy product consumption. An interesting sub-group in our dataset is the British 'healthconscious' group. With a reported consumption of dairy products of about $200 \mathrm{~g} \mathrm{day}^{-1}$, these subjects are in the lower range of consumption, although not at all in a unique position. Their consumption of meat and meat products is overall, however, far lower than that reported from all other centres and the cohort includes a large number of vegetarians (who eat no meat or fish) and vegans (who eat no animal products at all). Thus, the EPIC data suggest that an effect of dairy products on a given outcome can be examined independently of the effect of meat.

In summary, the present study reveals a wide range in the total consumption of dairy products and in the kinds of dairy products consumed within the EPIC centres. Also, the data suggest that dairy consumption may not necessarily correlate with the consumption of meat. Together with all the comprehensive information collected in the EPIC study, this provides an excellent basis for more thorough examinations of associations between dairy product intake and diseases and for gaining more knowledge of the various features of dairy products.

\section{Acknowledgements}

The work described in this paper was carried out with financial support of the 'Europe Against Cancer' Programme of the European Commission (SANCO); Ligue contre le Cancer (France); Société 3M (France); Mutuelle Générale de l'Education Nationale; Institut National de la Santé et de la Recherche Médicale (INSERM); Institute Gustave Roussy; German Cancer Aid; German Cancer Research Centre; German Federal Ministry of Education and Research; Danish Cancer Society; Health Research Fund (FIS) of the Spanish Ministry of Health; the Spanish Regional Governments of Andalucia, Asturias, Basque Country, Murcia and Navarra; Cancer Research UK; Medical Research Council, UK; Stroke Association, UK; British Heart Foundation; Department of Health, UK; Food Standards Agency, UK; Wellcome Trust, UK; Greek Ministry of Health; Greek Ministry of Education; Italian Association for Research on Cancer; Italian National Research Council; Dutch Ministry of Public Health, Welfare and Sports; Dutch Prevention Funds; LK Research Funds; Dutch ZON (Zorg Onderzoek Nederland); World Cancer Research Fund; Swedish Cancer Society; Swedish Scientific Council; Regional Government of Skane, Sweden; Norwegian Cancer Society; Norwegian Research Council. Partial support for the publication of this supplement was provided by the Centre de Recherche et d'Information Nutritionnelles (CERIN).

In addition, we wish to thank all study participants for their co-operation and all interviewers who participated in the fieldwork studies in each EPIC centre.

\section{References}

1 Fung TT, Rimm EB, Spiegelman D, Rifai N, Tofler GH, Willett 
WC, et al. Association between dietary patterns and plasma biomarkers of obesity and cardiovascular disease risk. Am. J. Clin. Nutr. 2001; 73: 61-7.

2 Heaney RP. Calcium, dairy products and osteoporosis. J. Am Coll. Nutr. 2000; 19(Suppl. 2): 83S-99S

3 Lunt M, Masaryk P, Scheidt-Nave C, Nijs J, Poor G, Pols H, et al. The effects of lifestyle, dietary dairy intake and diabetes on bone density and vertebral deformity prevalence: the EVOS study. Osteoporos. Int. 2001; 12: 688-98.

4 Kuller LH. Dietary fat and chronic diseases: epidemiologic overview. J. Am. Diet. Assoc. 1997; 97(Suppl.): S9-15.

5 Kwiterovich PO. The effect of dietary fat, antioxidants, and pro-oxidants on blood lipids, lipoproteins, and atherosclerosis. J. Am. Diet. Assoc. 1997; 97(Suppl.): S31-41.

6 Morgan S. Calcium and vitamin D in osteoporosis. Rheum. Dis. Clin. North Am. 2001; 27: 101-27.

7 World Cancer Research Fund (WCRF)/American Institute for Cancer Research (AICR). Food, Nutrition and the Prevention of Cancer: A Global Perspective. Washington, DC: WCRF/AICR, 1997.

8 Ursin G, Bjelke E, Heuch I, Vollset SE. Milk consumption and cancer incidence: a Norwegian prospective study. $\mathrm{Br}$ J. Cancer 1990; 61: 454-9.

9 Wolk A, Lindblad P, Adami HO. Nutrition and renal cell cancer. Cancer Causes Control 1996; 7: 5-18.

10 Giovannucci E. Dietary influences of $1,25(\mathrm{OH})_{2}$ vitamin D in relation to prostate cancer. Cancer Causes Control 1998; 9 567-82.

11 Chan JM, Stampfer MJ, Ma J, Gann PH, Gaziano JM, Giovannucci EL. Dairy products, calcium, and prostate cancer risk in the Physicians' Health Study. Am.J. Clin. Nutr. 2001; 74: 549-54.

12 Michaud DS, Augustsson K, Rimm EB, Stampfer MJ, Willett WC, Giovannucci E. A prospective study on intake of animal products and risk of prostate cancer. Cancer Causes Control 2001; 12: 557-67

13 Slimani N, Norat T, Hietanen E, Vainio H, Riboli E. Lait et cancer. In: Debry G, ed. Lait, nutrition et santé. Paris: Lavoisier, 2001; 277-340.

14 Newmark HL, Wargovich MJ, Bruce WR. Colon cancer and dietary fat, phosphate, and calcium: a hypothesis. J. Natl. Cancer Inst. 1984; 72: 1323-5.

15 Järvinen R, Knekt P, Hakulinen T, Aromaa A. Prospective study on milk products, calcium and cancers of the colon and rectum. Eur. J. Clin. Nutr. 2001; 55: 1000-7.

16 Valjinac HD, Marinković JM, Ilić MD, Kocev NI. Diet and prostate cancer: a case-control study. Eur. J. Cancer 1997; 33: $101-7$.

17 Russo GL, Pietra VD, Mercurio C, Palumbo R, Iacomino G, Russo M, et al. Protective effects of butyric acid in colon cancer. Adv. Exp. Med. Biol. 1999; 472: 131-47.

18 Devery R, Miller A, Stanton C. Conjugated linoleic acid and oxidative behaviour in cancer cells. Biochem. Soc. Trans. 2001; 29: 341-4.

19 Bounous G. Whey protein concentrate (WPC) and glutathione modulation in cancer treatment. Anticancer Res. 2000; 20: 4785-92.

20 Hove H, Nørgaard H, Mortensen PB. Lactic acid and the human gastrointestinal tract. Eur. J. Clin. Nutr. 1999; 53 339-50.

21 Ma J, Giovannucci E, Pollak M, Chan JM, Gaziano JM, Willett $\mathrm{W}$, et al. Milk intake, circulating levels of insulin-like growth factor-I, and risk of colorectal cancer in men. J. Natl. Cancer Inst. 2001; 93: 1330-6.

22 Alavanja MCR, Field RW, Sinha R, Brus CP, Shavers VL, Fisher $\mathrm{EL}$, et al. Lung cancer risk and red meat consumption among Iowa women. Lung Cancer 2001; 34: 37-46.

23 Visonneau S, Cesano A, Tepper SA, Scimeca JA, Santoli D, Kritchevsky D. Conjugated linoleic acid suppresses the growth of human breast cancer adenocarcinoma cells in SCID mice. Anticancer Res. 1997; 17: 969-74.

24 Aro A, Männistö S, Salminen I, Ovaskainen M-L, Kataja V, Uusitupa M. Inverse association between dietary and serum conjugated linoleic acid and risk of breast cancer. Nutr. Cancer 2000; 38: 151-7.

25 Nelson M, Bingham SA. Assessment of food consumption and nutrient intake. In: Margetts BM, Nelson M, eds. Design Concepts in Nutritional Epidemiology. Oxford: Oxford University Press, 1997; 123-69.

26 Buzzard M. 24-Hour dietary recall and food records methods. In: Willett W, ed. Nutritional Epidemiology. New York: Oxford University Press, 1998; 50-73.

27 Riboli E, Kaaks R. The EPIC project: rationale and study design. Int. I. Epidemiol. 1997; 26(Suppl. 1): S6-14.

28 Riboli E, Hunt KJ, Slimani N, Ferrari P, Norat T, Fahey M, et al. European Prospective Investigation into Cancer and Nutrition (EPIC): study populations and data collection. Public Health Nutr. 2002; 5(6B): 1113-24.

29 Slimani N, Kaaks R, Ferrari P, Casagrande C, Clavel-Chapelon $\mathrm{F}$, Lotze $\mathrm{G}$, et al. European Prospective Investigation into Cancer and Nutrition (EPIC) calibration study: rationale, design and population characteristics. Public Health Nutr. 2002; 5(6B): 1125-45.

30 Overvad K, Tjønneland A, Haraldsdóttir J, Ewertz M, Møller Jensen $O$. Development of a semiquantitative food frequency questionnaire to assess food, energy and nutrient intake in Denmark. Int. J. Epidemiol. 1991; 20: 900-5.

31 Tjønneland A, Overvad K, Haraldsdóttir J, Bang S, Ewertz M, Møller Jensen O. Validation of a semiquantitative food frequency questionnaire developed in Denmark. Int. J. Epidemiol. 1991; 20: 906-12.

32 Hjartåker A, Lund E, Bjerve KS. Serum phospholipid fatty acid composition and habitual intake of marine foods registered by a semi-quantitative food frequency questionnaire. Eur. J. Clin. Nutr. 1997; 51: 736-42.

33 Margetts BM, Pietinen P, Riboli E, eds. EPIC: European Prospective Investigation into Cancer and Nutrition: validity studies on dietary assessment methods [special issue]. Int J. Epidemiol. 1997; 26(Suppl. 1): S1-189.

34 Slimani N, Ferrari P, Ocké M, Welch A, Boeing H, van Liere $\mathrm{M}$, et al. Standardization of the 24-hour diet recall calibration method used in the European Prospective Investigation into Cancer and Nutrition (EPIC): general concepts and preliminary results. Eur. J. Clin. Nutr. 2000; 54: 900-17.

35 Slimani N, Deharveng G, Charrondière RU, van Kappel AL, Ocké M, Welch A, et al. Structure of the standardized computerized 24-h diet recall interview used as reference method in the 22 centers participating in the EPIC project. Comput. Meth. Programs Biomed. 1999; 58: 251-66.

36 Brustad M, Skeie G, Braaten T, Slimani N, Lund E. Comparison of telephone versus face-to-face interviews in the assessment of dietary intake by the 24-hour recall EPICSOFT programme - the Norwegian calibration study. Eur. J. Clin. Nutr. 2002; in press.

37 Agudo A, Slimani N, Ocké MC, Naska A, Miller AB, Kroke A, et al. Consumption of vegetables, fruit and other plant foods in the European Prospective Investigation into Cancer and Nutrition (EPIC) cohorts from 10 European countries. Public Health Nutr. 2002; 5(6B): 1179-96.

38 Keinan-Boker L, Peeters PHM, Mulligan AA, Navarro C, Slimani N and the EPIC Study Group on Soy Consumption. Soy product consumption in 10 European countries: the European Prospective Investigation into Cancer and Nutrition (EPIC) study. Public Health Nutr. 2002; 5(6B): 1217-26.

39 Linseisen J, Kesse E, Slimani N, Bueno-de-Mesquita HB, Ocké MC, Skeie G, et al. Meat consumption in the European Prospective Investigation into Cancer and Nutrition (EPIC) cohorts: results from 24-hour dietary recalls. Public Health Nutr. 2002; 5(6B): 1243-58. 
40 Linseisen J, Bergström E, Gafá L, González CA, Thiébaut A, Trichopoulou A, et al. Consumption of added fats and oils in European Prospective Investigation into Cancer and Nutrition (EPIC) centres across 10 European countries as assessed by 24-hour dietary recalls. Public Health Nutr. 2002; 5(6B): 1227-42.

41 Sieri S, Agudo A, Kesse E, Klipstein-Grobusch K, San-José B, Welch AA, Krogh V, et al. Patterns of alcohol consumption in 10 European countries participating in the European Prospective Investigation into Cancer and Nutrition (EPIC) project. Public Health Nutr. 2002; 5(6B): 1287-96.

42 Welch AA, Lund E, Amiano P, Dorronsoro M, Brustad M, Kumle M, et al. Variability of fish consumption within the 10 European countries participating in the European Prospective Investigation into Cancer and Nutrition (EPIC) study. Public Health Nutr. 2002; 5(6B): 1273-85.

43 Wirfält E, McTaggart A, Pala V, Gullberg B, Frasca G, Panico $\mathrm{S}$, et al. Food sources of carbohydrates in a European cohort of adults. Public Health Nutr. 2002; 5(6B): 1197-215.

44 Kleinbaum DG, Kupper LL, Muller KE. Applied Regression Analysis and Other Multivariate Methods, 2nd ed. Belmont, CA: Duxbury Press, 1988.

45 Ferrari P, Slimani N, Ciampi A, Trichopoulou A, Naska A, Lauria C, et al. Evaluation of under- and overreporting of energy intake in the 24-hour diet recalls in the European Prospective Investigation into Cancer and Nutrition (EPIC). Public Health Nutr. 2002; 5(6B): 1329-45.

46 Lagiou P, Trichopoulou A, Henderickx HK, Kelleher C, Leonhauser IU, Moreiras O, et al. for the DAFNE I and II projects of the European Commission. Household budget survey nutritional data in relation to mortality from coronary heart disease, colorectal cancer and female breast cancer in European countries. Eur. J. Clin. Nutr. 1999; 53: 328-32.

47 Trichopoulou A, Naska A, eds. The DAFNE Initiative. Assessment of dietary patterns across Europe using household budget survey data. A European Commission supported project [special issue]. Public Health Nutr. 2001; 4(5B): 1129-98.
48 Food and Agriculture Organization [online], 2001. Available at http://apps.fao.org/lim500/wrap.pl?FoodBalanceSheet\& Domain $=$ Food BalanceSheet\&Language $=$ English .

49 Sahi T. Hypolactasia and lactase persistence. Historical review and terminology. Scand. J. Gastroenterol. Suppl. 1994; 202: 1-6.

50 Sahi T. Genetics and epidemiology of adult-type hypolactasia. Scand. J. Gastroenterol. Suppl. 1994; 202: 7-20.

51 Gudmand-Høyer E, Skovbjerg H. Disaccharide digestion and maldigestion. Scand. J. Gastronterol. 1996; 31(Suppl. 216): $111-21$.

52 Knekt P, Järvinen R, Seppänen R, Pukkala E, Aromaa A. Intake of dairy products and the risk of breast cancer. $\mathrm{Br}$. J. Cancer 1996; 73: 687-91.

53 Hjartåker A, Laake P, Lund E. Childhood and adult milk consumption and risk of premenopausal breast cancer in a cohort of 48,844 women - The Norwegian Women and Cancer Study. Int. J. Cancer 2001; 93: 888-93.

54 Pietinen P, Malila N, Virtanen M, Hartman TJ, Tangrea JA, Albanes D, et al. Diet and risk of colorectal cancer in a cohort of Finnish men. Cancer Causes Control 1999; 10: 387-96.

55 Sandler RS, Lyles CM, Peipins LA, McAuliffe CA, Woosley JT, Kupper LL. Diet and risk of colorectal adenomas: macronutrients, cholesterol, and fiber. J. Natl. Cancer Inst. 1993; 85: $884-91$.

56 Favero A, Parpinel M, Montella M. Energy sources and risk of cancer of the breast and colon-rectum in Italy. $A d v$. Exp. Med. Biol. 1999; 472: 51-5.

57 Bingham SA. High-meat diets and cancer risk. Proc. Nutr. Soc. $1999 ;$ 58: 243-8.

58 Norat T, Riboli E. Meat consumption and colorectal cancer: a review of epidemiologic evidence. Nutr. Rev. 2001; 59: $37-47$.

59 Sandhu MS, White IR, McPherson K. Systematic review of the prospective cohort studies on meat consumption and colorectal cancer risk: a meta-analytical approach. Cancer Epidemiol. Biomark. Prev. 2001; 10: 439-46. 